\title{
Galantamine Pharmacological Screening and Toxicology
}

\author{
Krishnasarma Pathy * \\ IPL Research Centre, India
}

Submission: : January 02, 2018; Published: January 24, 2018

*Corresponding author: Krishnasarma Pathy, Head QC/QA, Dr. Saeed Khan limra hospital, MD (Integ. Medicine) MBA (Hospital Admin), India, Email: drkrishnasarmapathy@yahoo.in

\begin{abstract}
Galantamine, an alkaloid isolated from the Caucasian snow-drop (Galanthus woronowii), is a selective, reversible and competitive inhibitor of acetyl cholinesterase (ACHE), as well as an allosteric modulator of the neural nicotinic receptor for acetylcholine. Galantamine is the most recently approved AChE inhibitor for the symptomatic treatment of Alzheimer's disease. Because of the limited supplies from natural sources, several total syntheses have been reported to produce this drug. Characterized in the early 1950s in Bulgaria, it saw limited use for paralytic and neuropathic conditions until the cholinergic hypothesis of Alzheimer's disease opened totally new perspectives for its utility. Although constricted supplies at extremely high prices and a fragmented patent situation made its repurposing challenging, galantamine was globally launched as an Alzheimer's disease drug in 2000. Galantamine can produce cholinomimetic effects. Overdose effects of cholinergic agonists generally involve the central nervous system, the parasympathetic nervous system, and the neuromuscular junction. Alantamine, a tertiary alkaloid, is a reversible, competitive and long-acting inhibitor of cholinesterase activity.
\end{abstract}

Keywords: Galantamine; Pharmacological Screening; Toxicology

\section{Introduction}

Galanthamine, an Amaryllidaceae alkaloid, has been used clinically for 30 years for treatment of myasthenia gravis 1 and other neurological illnesses such as poliomyelitis, 2 as an anti-curare agent, 3 and as a parasympathomimetic. 4 More importantly, it has been approved for the treatment of Alzheimer's disease in Austria and is in phase III clinical trials both in the United Kingdom and the Unites States. 5-6 Galanthamine is produced by isolation from botanical sources (e.g. Galanthus niValis, G. narcissus, G. leucojum, or G.crinium7-9); despite renewed efforts, 9 these sources are not suitable for generation of large enough quantities of galanthamine (Figure 1). We had requirements for large quantities of galanthamine for in vitro and in vivo efficacy studies and pharmacokinetic studies. Galanthamine was first synthesised by Barton 10 with a pivotal synthetic step being an oxidative phenol cyclization ( $0.5 \%$ yield). Other researchers were able to increase both the yields and the scale of the Barton procedure. Other syntheses of galanthamine have been reported [1-5].

\section{Discussion}

Although plants used medicinally are widely assumed to be safe, many are potentially toxic. Where poisoning from traditional medicines has been reported, it is usually because the plants used have been misidentified in the form in which they are sold, or incorrectly prepared and administered by inadequately trained personnel. The issue of quality control may, in the interim, be addressed using chromatographic techniques. Alzheimer's disease is characterised by a progressive impairment of cognitive function including the loss of memory and the inability to perform basic daily life activities Francis, 1999. Recently, the Amaryllidaceae alkaloid galanthamine (Figure 1) has been approved in a number of European countries for the treatment of Alzheimer's disease Wilkinson and Murray, 2001. Although galan-thamine was originally isolated from European amaryllids it s also found in several traditionally used African Amaryl-lidaceae Viladomat, 1997. Galanthamine \& other acetyl cholinesterase enzyme (AChE) inhibitors alleviate the symptoms of Alzheimer's disease by inhibiting the activity of AChE and hence maintain or elevate the levels of acetylcholine in the brain Sramek, 2000 [5-10].

Twenty-two Amaryllidaceae alkaloids of various ring types from Crinum moorei Hook. f. (Amaryllidaceae), Crinum macowanii Bak. (Amaryllidaceae), Crinum bulbispermum (Burm.) Milne-Redhead and Schweickerdt (Amaryllidaceae) and Cyrtanthus falcatus R.A. Dyer (Amaryllidaceae) were screened for AChE inhibition activity Elgorashi, 2004. The alkaloid 1-0-acetyllycorine (Figure1) (IC50: 0.96 \pm 0.04 ? M) was twice as

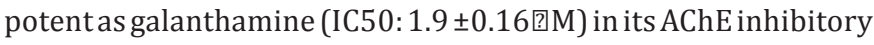


activity. Plant adaptogens promote a non-specific increase in the body's resistance to various naturally occurring harmful agents. Various studies have shown that adaptogenic plants affect the nervous system, improving cognitive functions by slowing down the deterioration of cognitive processes observed in elderly people. The southern African amaryllid Brunsvi-gia grandifolia Lindl. And members of the genus Crinum, are used traditionally as such 'tonics' Hutchings, 1996. Both contain galanthamine Viladomat, 1997. Other traditionally used tonics, Clausena anisata and Catha edulis (Vahl) Endl. (Celastraceae), are recognized scientifically for their psychotropic activity (Figure 1) [10-15].

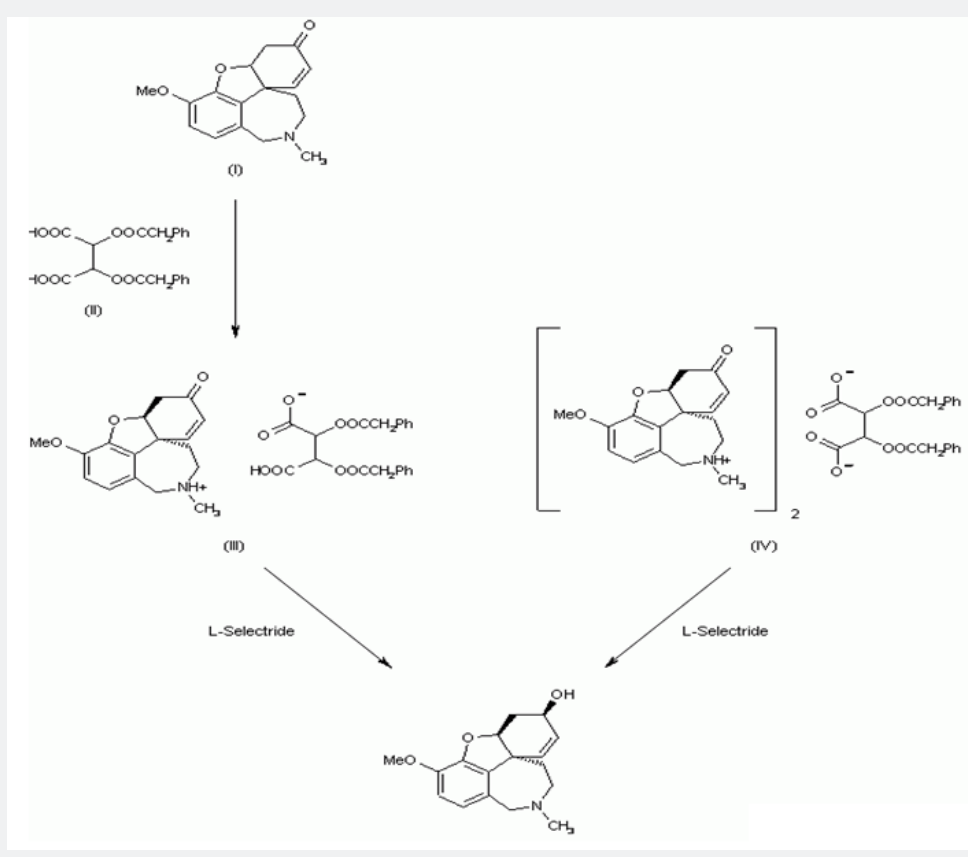

Figure 1.

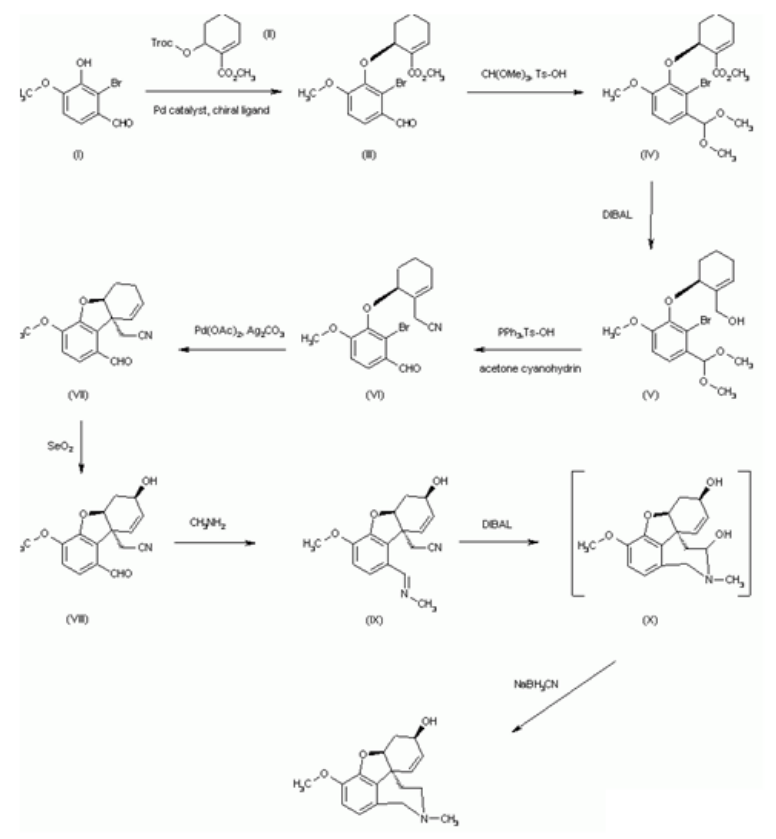

Figure 2.

Dynamic diastereomeric salt resolution of narwedine and its transformation to (-)-galanthamine. The salification of racemic narwedine (I) with di-p-toluoyl-D-tartaric acid (II) produces high yields of the 1:1 (III) or the 2:1 (IV) salts with a high enantiomeric enhancement ( $97 \%$ and $98 \%$ e.e., respectively), a dynamic optical enrichment being produced. In a second step, salts (III) and (IV) 
are reduced to (-)-galanthamine with L-Selectride, which is finally purified up to $>99 \%$ e.e. by crystallization of its hydro bromide. An efficient enantioselective synthesis of (-)-galanthamine The condensation of 2-bromo-3-hydroxy-4-methoxybenzaldehyde (I) with the cyclohexenecarboxylate (II) by means of a Pd catalyst and a chiral auxiliary gives the chiral aryl ether (III), which is treated with methyl orthoformate and Ts- $\mathrm{OH}$ in methanol to yield the dimethylacetal (IV). The reduction of the ester group of (IV) by means of DIBAL affords the methanol derivative (V), which is treated with acetone cyanohydrin, $\mathrm{PPh} 3$ and Ts- $\mathrm{OH}$ to provide the acetonitrile derivative (VI). The cyclization of (VI) by means of $\mathrm{Pd}(\mathrm{OAc}) 2$ and $\mathrm{Ag} 2 \mathrm{CO} 3$ in refluxing toluene leads to the tetra hydro dibenzofuran derivative (VII), which is diastereoselectively oxidized by means of $\mathrm{SeO} 2$ in hot dioxane to give the chiral secondary alcohol (VIII). The reaction of (VIII) with methylamine in methanol yields the methylamine (IX), which is submitted to reductocyclization by means of DIBAL to afford the tetra cyclic intermediate (X). This compound, without isolation, is reduced with $\mathrm{NaBH} 3 \mathrm{CN}$ to provide the target galanthamine (Figure 2) [15-20].

\section{Conclusion}

In an extensive screening programme of plants used in traditional medicine, researchers provided scientific evidence for their rational use in treating infections and diseases, inflammation, and disorders of the central nervous system. Using the ethnobotanical approach and bioassay-guided fractionation, several compounds having biological activity were isolated and identified. Genotoxicity studies also showed that several plants used for medicinal purposes cause damage to the genetic material and, therefore, should be used with caution. Cases of acute poisoning are also not uncommon, but chromatographic techniques are now proving useful in the authentication of plants and plant parts sold at medicinal plant markets in South Africa.

\section{References}

1. Anonymous (1983) Synform 283.

2. Czollner L, Frantsits W, Kuenburg B, Hedenig U, Frohlich J, et al. (1998) 39: 2087.

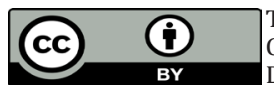

This work is licensed under Creative Commons Attribution 4.0 License DOI: 10.19080/JPCR.2018.05.555653
3. Chaplin DA, Fraser N, Tiffin PD (1997) A concise, scaleable synthesis of narwedine. Tetrahedron Lett 38: 7931-7932.

4. The same process was presented in more detail: McCague R (2015) Complete Industrial Total Synthesis of the Alkaloid (-)-Galanthamine; presented at Chiral USA, San Francisco, USA.

5. Pschorr R (1912) Über die Bromierung von m-Oxybenzaldehyd, Vanillin und Homovanillinsäure. Ann Chem 391(1): 23-39.

6. Bretherick L (1981) Hazards in the Chemical Laboratory ( $3^{\text {rd }}$ edn). Royal Society of Chemistry London, p. 99.

7. Brossi A, Gurien H, Rachlin A (1967) Teitel. S J Org Chem 32: 1269.

8. Bulavka BH, Tolkatschew OH, Tschawlinskij AH (1990) Khim Farm Zh 24: 59 .

9. Henry H, Sharp TM (1930) J Chem Soc pp. 2279

10. Pauli H (1915) Chem Ber 48: 2010.

11. Raiford L, Ravely M (1940) J Chem Soc pp. 204.

12. Bulavka V, Tolkatschew OH, Tschawlinskij AH (1991) Khim Farm Zh 25: 46.

13. Adewunmi CO, Oguntimein BO, Furu P (1990) Molluscicidal and antischistosomal activities of Zingiber officinale. Planta Medica 56(4): 374-376.

14. Anyinam C (1995) Ecology and ethnomedicine: exploring links between current environmental crisis and indigenous medical practices. Social Science Medicine 40(3): 321-329.

15. Arnold TH, Prentice CA, Hawker LC, Snyman EE, Tomalin M, et al. (2002) Medicinal and magical plants of southern Africa: an annotated checklist. Strelitzia XIII. National Botanical Institute, South Africa.

16. Awe SO, Makinde JM (1998) Evaluation of sensitivity of Plasmodiumfalciparum to Morinda lucida leaf extract sample using rabbit in vitromicrotest technique. Indian Journal of Pharmacology 30(1): 51-53.

17. Bergman RL (1973) A school for medicine men. American Journal of Psychiatry 130(6): 663-666.

18. Bienvenu E, Amabeoku GJ, Eagles PK, Scott G, Springfield EP (2002) Anticonvulsant activity of aqueous extract of Leonotis leonurus. Phytomedicine 9(3): 217-223.

19. Bodenstein JW (1973) Observations on medicinal plants. South African Medical Journal 47 (8): 336-338.

20. Bodenstein JW (1977) Toxicity of traditional herbal remedies. South African Medical Journal 52(20): 790.

\section{Your next submission with Juniper Publishers will reach you the below assets}

- Quality Editorial service

- Swift Peer Review

- Reprints availability

- E-prints Service

- Manuscript Podcast for convenient understanding

- Global attainment for your research

- Manuscript accessibility in different formats

(Pdf, E-pub, Full Text, Audio)

- Unceasing customer service

Track the below URL for one-step submission

https://juniperpublishers.com/online-submission.php 